\title{
The Associations of Different Social Needs with Psychological Strengths and Subjective Well-Being: An Empirical Investigation Based on Social Production Function Theory
}

\author{
Nardi Steverink ${ }^{1,2}$ (D) Siegwart Lindenberg ${ }^{1,3} \cdot$ Tali Spiegel $^{4} \cdot$ Anna P. Nieboer $^{5}$
}

Published online: 29 March 2019

(c) The Author(s) 2019

\begin{abstract}
The fulfilment of social needs is essential for human beings to function well and thrive, but little is known about how social needs are differentially associated with types of well-functioning. This study investigates how the three social needs as proposed by Social Production Function theory - the needs for affection, behavioral confirmation, and status-relate to psychological strengths (self-evaluation, hope, and self-regulatory ability), loneliness, and subjective well-being (life satisfaction, positive and negative affect). Moreover, possible mechanisms are explored. Using the first release sample of the LifeLines study $(\mathrm{N}=13,301)$ and four other samples $(\mathrm{N}=1094, \mathrm{~N}=456, \mathrm{~N}=415$, and $\mathrm{N}=142)$, we found that the three social needs yielded a robust factor structure, and related differentially to gender and education. Their associations with all three psychological strengths were substantial. Affection need fulfilment related most strongly to both emotional and social loneliness, but the expected stronger association of behavioral confirmation with social loneliness was not found. As expected, affection related most strongly to life satisfaction and least strongly to positive affect, whereas status related most strongly to positive affect and least strongly to life satisfaction. Of all social needs, behavioral confirmation had comparatively the strongest negative association with negative affect. With regard to mechanisms, affection was found to have a partial indirect effect on life satisfaction via self-evaluation, hope, and self-regulatory ability, while status had a modest indirect effect via self-regulatory ability on positive affect. It is concluded that different need fulfillments make unique contributions to different types of well-functioning, implying that a mix of social need satisfiers (i.e. different kinds of social relationships and other social provisions) are needed for individuals to function well. This knowledge may support interventions and policy directed at both individual and societal well-being.
\end{abstract}

Keywords Social needs - Social production function theory - Subjective well-being · Psychological strengths

Nardi Steverink

b.j.m.steverink@rug.nl

Extended author information available on the last page of the article 


\section{Introduction}

In recent years there has been a renewed interest in universal basic and psychosocial needs, the fulfillment of which has been shown to be essential to positive functioning and wellbeing (e.g., Deci and Ryan 2000; Demir and Özdemir 2010; Diener et al. 2010; Tay and Diener 2011). 'Needs' refer to certain basic physical and social needs, such that deficits in their satisfaction create negative psychological consequences. Especially social needs, such as the need for close relationships and respect from others, have been found to be strong predictors of happiness and positive feelings (e.g., Diener et al. 2010). A study by Tay and Diener (2011) has shown the association of social needs with well-being in countries all over the world. Conversely, deficits and deprivations in social needs fulfillment have been shown to lead to pathological and aversive outcomes. For example, evidence from the social neurosciences shows that social rejection creates social pain, which is visible in the brain in a way similar to physical pain (e.g., Eisenberger et al. 2003). So, overall, it is a core finding in the literature that social need fulfilment is crucial for subjective wellbeing and happiness in general, and deficits in social need fulfilment lead to social pain and unhappiness. What has not received much attention so far, however, is the question whether the fulfilment of different social needs is related to different socially and psychologically important outcomes, and what the possible mechanisms are that underlie these associations. The aim of this paper is, therefore, to investigate to what extent different social needs relate differentially to indicators of well-functioning, and to explore possible mechanisms.

In order to answer these questions empirically, it is important to know, first of all, which social needs to distinguish. Lack of attention to the question how the fulfilment of different social needs affects various outcomes, may be related to the fact that many prominent theories of social needs assume that there is basically one overall social need. For example, Baumeister and Leary (1995) do consider the need for intimacy or affection, the need for approval and affiliation, and the need for power, but they consider these needs as derivatives of the overarching need to belong (see Baumeister and Leary 1995, p. 498, 522). Also Deci and Ryan (2000), when talking about the need for relatedness, refer to love and care, which seem to point to a need for intimacy and affection, but at the same time they also identify relatedness as "assimilation and integration of oneself within the social community" (Deci and Ryan 2000, p. 242), which seems to refer to the wider group rather than to intimate relationships. So, it still is uncertain which social needs to distinguish. This may have caused that, so far, little attention has been paid to the question whether deficits in different social need fulfilments may have different consequences for indicators of wellfunctioning. For example, if there is a need to relate to others, then there is one kind of social need deficit: lack of relations to others. If, by contrast, the presumed need to relate is actually a combination of a need for intimate relations and a need to be socially accepted, there could be two different kinds of deficits. Having a deficit in one social need does not necessarily mean that one also has a deficit in the other: people can feel accepted by members of a group but not have intimate relationships with them and vice versa, with also different consequences for specific outcomes of well-functioning.

In this paper, a distinction of three fundamental social needs, as proposed by Social Production Function (SPF) theory (Lindenberg 2013), will be used. SPF theory distinguishes three basic social needs, next to two basic physical needs (for detailed descriptions see Lindenberg 2013; Steverink 2014). The two basic physical needs are comfort and stimulation, but in this paper we focus on the three social needs: affection, behavioral confirmation, and status. Affection is the feeling that you are liked and loved. Affection thus refers to the love 
you get for being who you are, regardless of your assets (status) or actions (behavioral confirmation). Behavioral confirmation is the feeling of doing the 'right' thing in the eyes of important others and yourself; it includes doing good things, doing things well, and being part of a functional group. Behavioral confirmation, thus, results primarily from what you do, rather than what you are (affection), or what you have or can do (status). Note that 'behavioral confirmation' was also used by Snyder and Swann (1978) to refer to the selffulfilling nature of social stereotypes. However, in our definition, behavioral confirmation is the confirmation that a person gets from others, or from herself, for showing the 'right' behavior. The third social need, status, is the feeling that you are being treated with respect, achieve more than others, have influence, and are known for your achievements, skills, or assets.

\subsection{How to Assess Social Needs?}

Mostly, needs are assessed by directly asking people about whether or not they have certain needs and to what extent. For example, the need to belong scale (Leary et al. 2013) uses items such as "I want other people to accept me" and "I have a strong need to belong". Such ways of assessing needs are useful when one is interested in individual differences in the strength of a need. However, a different approach seems necessary in order to distinguish different needs and their different associations with relevant outcomes. SPF theory proceeds from the idea that for purposes of distinguishing social needs and tracing their consequences, one should be able to distinguish their alleged 'satisfiers' and, pari passu, the possible different deficits and consequences of deficits. In the case of social needs, need 'satisfiers' would be those social relationships and/or social phenomena or social situations that are evaluated by a person as satisfying one or more social needs. For example, emotionally close relationships, which make a person feel that he or she is being loved, are need satisfiers for the need for intimate and close connections. Similarly, responses from others that make a person feel that he or she is ranked higher than others, are satisfiers for the need for prestige or status.

Baumeister and Leary (1995) and Deci and Ryan (2000) would be justified in lumping social needs together in one global need, if the various social needs are in fact fulfilled by the same satisfiers. Some satisfiers, such as the relationship with a spouse or parent, may indeed fulfil different social needs at the same time. Thus, need fulfillment of the three social needs will be correlated to some degree. However, if indeed there are different social needs, there should also be different satisfiers for these needs and different outcomes if the satisfiers are subjectively present or absent to various degrees.

Using focus groups and applying detailed content analysis, Van Bruggen (2001) has investigated potential satisfiers of the three social needs affection, behavioral confirmation and status. She identified various social relationships and various social situations, that differentially fulfill the separate social needs. For example, the satisfiers for the need for affection are relationships that give you the feeling that you are liked, loved, understood, empathized with, feel that others are willing to help without expecting something in return, feel that your well-being is intertwined with that of others, and feel that others like to be either emotionally or physically close to you (e.g., to hug) and reciprocate your feeling. Satisfiers for the need for behavioral confirmation are relationships that give you the feeling of doing the 'right' thing in the eyes of important others and yourself; it includes doing good things, doing things well, being a good person, being useful, contributing to a common goal, and being part of a group. Finally, satisfiers for the need for status are 
relationships that give you the feeling that you are being treated with respect and are being taken seriously, achieve more than others, have influence, and are known for your achievements, skills or assets.

On the basis of Van Bruggen's work, Nieboer et al. (2005) constructed and tested an instrument for measuring the three social need fulfilments. This instrument (called the SPF-IL) contained 18 items for affection and 12 items each for behavioral confirmation and status. The original scale also contained 8 items each for measuring the two physical needs of SPF theory (comfort and stimulation), next to the three social needs. Nieboer et al. (2005) tested the scales in various studies and, in general, found acceptable psychometric properties for the three social need scales, and the two physical needs scales. This work produced the first systematic evidence for distinguishing the three social needs. However, since an instrument with so many items is unwieldy, Nieboer et al. also developed short versions of the scales with three items for each social and physical need. The shortened scales (called SPF-IL(s)) have been used in many studies (e.g., Cramm and Nieboer 2015; Frieswijk et al. 2006; Goedendorp and Steverink 2017; Nieboer and Cramm 2017), and was recently validated again with various samples of older populations (Nieboer and Cramm 2018).

\subsection{The Three Needs and Indicators of Well-Functioning in Various Samples}

In order to investigate the differential associations of the three social need fulfilments with indicators of well-functioning, both psychological strengths and subjective well-being outcomes will be considered as indicators of well-functioning and thriving. Well-functioning and experiencing well-being, as argued previously, are inherently dependent on being socially well provided, i.e. having one's basic social needs fulfilled.

In order to investigate the presumed associations in a robust way, we had available five samples, including a unique sample of more than 13,000 participants with an age range of 18-90 years, which contained, next to the three social needs, at least some measures of psychological strengths and/or subjective well-being. These allowed us to test whether or not specific deficits/fulfillments of the various social needs indeed have specific associations with these indicators of well-functioning. In the following these indicators will be explained in more detail.

\section{Hypotheses}

\subsection{The Three Social Needs Among Various Populations}

Before going into the differential associations of the three social need fulfilments with various indicators of well-functioning, the first question to be answered is whether the three social needs are robustly distinguishable in various populations. Studies so far have shown consistent results. For example, Nieboer et al. (2005) showed that the three social needs could be reliably and validly measured in adults aged 18-65. Steverink and Lindenberg (2006) found the three social needs reliably measured in community-dwelling older adults aged 65 and over, as did Nieboer and Cramm in various samples of communitydwelling older adults aged 70 and over (Cramm and Nieboer 2015; Nieboer and Cramm 2017, 2018). The latter study also found the three social needs in frail older people aged 70 and over, and in Turkish migrants aged 65 and over (Nieboer and Cramm 2018). Thus, 
although most previous studies included only older adults, it is expected that the factor structure of the three social needs is robustly replicated in the five samples of the present study (Hypothesis 1).

\subsection{Demographics}

A second question is what the associations are of the different social needs fulfilments with the demographic variables age, gender, and level of education. Regarding age it is expected that, due to the diminishing availability of need satisfiers at advanced age, levels of need fulfilment will decrease with age, but this decline will be relatively small for affection and relatively large for status, while for behavioral confirmation it will lie in-between affection and status. This is expected, because need satisfiers for affection are relatively "age-proof" (e.g., contact with close relatives, friends), while those for status (e.g., prestige from education, work and other assets) often decrease at older ages (Mayr et al. 2012; Steverink and Lindenberg 2006). These age-related expectations for the three social needs are referred to as Hypothesis $2 \mathrm{a}$.

Regarding gender, associations are mainly expected for affection and status rather than for behavioral confirmation. Although both affection and status are assumed to be basic social needs in both men and women, there are gender-specific advantages in how people are able to fulfill these needs and how to compensate between need fulfilments (cf. Steverink et al. 2011). Women have physiological and socialization advantages for fulfilling the need for affection (e.g., Maccoby 1990; Taylor et al. 2002), whereas men have these advantages for status need fulfillment (Baumeister and Sommer 1997). Therefore, it is expected that higher levels of fulfillment of the need for affection will be found in women as compared to men, and higher levels of status need fulfillment will be found in men as compared to women; as the fulfillment of the need for behavioral confirmation depends on social roles and group memberships, we have no expectations that these conditions will systematically differ for men and women (Hypothesis $2 b$ ).

Also an association between level of education and status need fulfillment is expected, because education is generally associated with higher social standing (Hauser et al. 2000). The association between education and status need fulfillment will thus be stronger than those between education and affection or behavioral confirmation needs fulfillment (Hypothesis 2c).

\subsection{Psychological Strengths}

Psychological strengths pertain to an individual's positive psychological characteristics that contribute to optimal functioning (Linley et al. 2010). Prominent examples of psychological strengths in the literature are hope, self-efficacy, resilience, and optimism, also referred to as psychological capital (Luthans and Youssef-Morgan 2017). Other examples are core self-evaluations (Liu et al. 2016), and self-regulatory ability (Lindenberg 2013). Given the inherently social nature of human beings, it may be expected that social satisfiers add to (or undermine) the development of psychological strengths. In the data, we had available three different concepts of what are considered important psychological strengths, i.e. positive self-evaluation, hope, and self-regulatory ability. We hypothesize that all three social need fulfilments are positively associated with these three psychological strengths (Hypothesis 3 ). Indeed, in the literature, some indications exist, that social need fulfilment is associated with psychological strengths. For example, social support was found to positively 
impact core self-evaluations (Liu et al. 2016), as did being liked and accepted (Leary and Baumeister 2000), and the experience of status achievement (e.g., Anderson et al. 2015). Close relationship satisfaction has been shown to increase positive self-evaluations, hope, and self-regulatory abilities (e.g., Hofmann et al. 2015), whereas deficits in social acceptance were found to lead to serious decreases in self-regulatory capacity (Baumeister et al. 2005).

\subsection{Loneliness}

Loneliness negatively affects people in many different ways. It has negative health effects (Cacioppo and Patrick 2010), it creates a sense of meaninglessness (Stillman et al. 2009) and it matters for cognitive functioning and mental health (Hawkley and Cacioppo 2010). Social relations indeed play an important role, but what social need deficit is most important for loneliness? It is expected that especially affection and behavioral confirmation relate to overall loneliness, while status need fulfilment will show no or a very weak correlation (Hypothesis 4a). This prediction is based on the fact that overall loneliness is conceptualized primarily in terms of contacts with more proximal relationships (i.e., those that can provide affection and some behavioral confirmation). When one distinguishes between emotional and social loneliness (Weiss 1973), affection need fulfilment is expected to correlate more strongly with emotional loneliness than with social loneliness, whereas behavioral confirmation need fulfilment is expected to correlate more strongly with social loneliness than with emotional loneliness (Hypothesis $4 \mathrm{~b}$ ).

\subsection{Indicators of Subjective Well-Being}

Three types of subjective well-being are considered here: life satisfaction, positive affect, and negative affect. These three are generally accepted as separable and distinct types of subjective well-being (e.g., Lucas et al. 1996). Life satisfaction is seen as a cognitive indicator, and thus the result of a cognitive evaluation of one's life as a whole. Positive and negative affect are considered as affective components and thus related to emotional states (Diener et al. 1999).

As stated in the introduction, the core idea of basic social needs is that their fulfillment enhances people's feelings of well-being, and that deficits in fulfillment are detrimental to well-being. However, based on earlier findings (Diener et al. 2010; Steverink and Lindenberg 2006; Tay and Diener 2011), it is expected that the fulfillment of the three social needs is differentially related to the three types of subjective well-being. An important reason for this is that the three need fulfilments are not the same with regard to satiation. Nieboer and Lindenberg (2002) showed empirically that once individuals have reached a minimum level of fulfilment of their need for affection, the satiation curve of affection levels off quickly. For status, they found the opposite, i.e., the satiation curve for status does not much level off. Possibly, because status is both a need and a resource (analogous to money), it is more difficult to satiate than the needs for affection and behavioral confirmation. Finally, it was found that behavioral confirmation lies in-between affection and status with regard to satiation.

Given the low rate of satiation of status, positive experiences that validate or increase status (such as being better than others, admired, shown respect and deference) contribute much to need fulfillment at the moment and should, therefore, be associated with activated positive emotions (such as alert, strong, full of pep, enthusiastic, proud). This 
is comparable to what Sheldon and Lyubomirsky (2006) found for the effects of "best possible selves" reflections. By contrast, positive experiences with affection (such as feeling that you are liked, loved, and understood) are likely to fall within the flat region of the satiation curve and therefore feel reassuring without much emotional arousal, contributing to life satisfaction ("I am satisfied with my life") rather than activated positive affect. It is thus expected that affection be associated most with life satisfaction, whereas status will be associated most with positive affect (Hypothesis 5a).

For negative affect it is harder to predict whether one of the social needs will have a stronger association. Deficits in each of the three needs may yield negative emotions. However, in line with the argument on satiation, and due to the fact that negative affect taps more into arousal than life satisfaction but less so than positive affect (negative affect also includes calmer negative mood states, such as guilty, afraid [rather than scared], ashamed, nervous [rather than jittery], sad), we expect the strongest association of negative affect to be with behavioral confirmation that lies in-between status and affection with regard to satiation (Hypothesis 5b).

Regarding the size of the correlations, they are expected to be in a range that is comparable to those of Tay and Diener (2011, p. 357), who found correlations for social needs with life satisfaction and positive affect between .12 and .24 (for the Northern Europe/ Anglo region), and with negative affect between -.10 and -.04 (same region).

\subsection{Possible Mechanisms}

In order to shed some light on possible mechanisms, we explore the possible mediating role of psychological strengths in the link between social needs fulfilment and indicators of subjective well-being, including loneliness. Indeed, being aware of and using one's psychological strengths is found to increase well-being over time (Wood et al. 2011). Moreover, psychological strengths (e.g., core self-evaluations, self-esteem and hope) are found to mediate the link between concepts that closely relate to social need fulfilments, such as social support, and indicators of well-functioning (Liu et al. 2016; Zhou et al. 2018). In general, one can glean from the literature that social relationships satisfy social needs, which, in turn, is energizing, increasing goal-striving and reducing stress. Steverink and Lindenberg (2008) found an indirect effect of having satisfying social relationships on life satisfaction and negative affect, mediated through self-regulatory capacity, i.e. the ability to take care of one's resources that contribute to well-being through having a positive frame of mind, taking initiative, and investment behavior. Research based on social baseline theory (Coan and Sbarra 2015) showed that close relationships increase one's bioenergetic resources and emotion regulation, and decreases stress reactions and the need for reappraisals. This, in turn, increases a cross-situational subjective appraisal of having goalrelated capabilities, a psychological strength defined as hope (Snyder et al. 2002). Hope as a psychological strength has been found to buffer against stressful life events (Valle et al. 2006), and is associated with being agentic and focused on goal-striving with numerous pathways for goal attainment (Snyder et al. 2002). Also Khan (2013) found mentoring (which prominently includes behavioral confirmation and affection need fulfilment) to add to well-being through its positive influence on, among others, hope. Thus, although social needs fulfilment is expected to have an important direct effect on indicators of well-being, the existing evidence suggests that the associations of social needs fulfilments with subjective well-being indicators are at least in part mediated by psychological strengths. 
Table 1 Characteristics of the five samples

\begin{tabular}{llllll}
\hline Samples & 1 & 2 & 3 & 4 & 5 \\
\hline Age range & $18-65$ & $18-90$ & $18-94$ & $68-100$ & $52-80$ \\
Mean age in years (SD) & $42.5(11.98)$ & $48.7(11.48)$ & $55.1(19.37)$ & $76.4(5.80)$ & $64.3(7.42)$ \\
Female (\%) & 52.5 & 58.2 & 56.4 & 54.0 & 100 \\
Married/living as married (\%) & 82.9 & 85.3 & 73 & 67.8 & 0 \\
\hline
\end{tabular}

Sample 1: Community-based sample of men and women $(\mathrm{N}=1094)$; Sample 2: Community-based sample of men and women $(N=13,301)$; Sample 3: Community-based sample of men and women $(N=456)$; Sample 4: Community-based sample of men and women $(N=415)$; Sample 5: Community-based sample of single women $(N=142)$

\section{Materials and Methods}

\subsection{The Samples}

We had available five different samples, in which the SPF-IL(s) scales, and one or more of the concepts needed to test our hypotheses, have been applied. These samples have been used for different study projects. The first sample $(N=1094)$ is the original main sample of Nieboer et al. (2005) in which the scales have been developed and tested, and which consists of a representative sample of the Dutch population in the age range of 18-65 years. The second sample $(N=13,301)$ concerns the first release (April 2012) of the Dutch LifeLines Cohort study (Scholtens et al. 2015). LifeLines is a multi-disciplinary prospective population-based cohort study examining in a unique three-generation design the health and well-being of persons living in the North of The Netherlands. The current study includes participants aged 18-90. The third sample $(N=456)$ consists of a communitybased sample of persons aged 18-94 participating in a Dutch study on well-being. The fourth sample $(N=415)$ contains a community-based sample of community-dwelling older people aged 68 and older who participated in a Dutch study on well-being and social comparison. Sample $5(N=142)$ consists of community-dwelling single women aged 52 and over, who signed up to take part in an intervention study on self-management abilities and well-being (Kremers et al. 2006). Of this latter sample we used the data of the pretest, before the women were randomized into the intervention versus the control group. Note that samples 1, 2 and 3 are samples of the general population, whereas sample 4 is special with respect to age $(68+)$, and sample 5 is special with respect to age $(52+)$, gender (only females) and marital status (all single). Table 1 shows the main demographic characteristics of all samples.

\subsection{Ethics Statement}

At the time the studies using samples 1, 3, and 4 were executed, they were exempt from ethical approval in the Netherlands. Participants were informed of the study's purpose and mode of participation. Participation was entirely voluntary, and data were handled confidentially. The study using sample 2 is conducted according to the principles of the Declaration of Helsinki and was approved by the medical ethical committee of the University Medical Center Groningen in The Netherlands. The study using sample 5 was evaluated by 
the medical ethical review committee of the University Medical Center Groningen, which approved the study and indicated that it was not subject to the Medical Research Involving Human Subjects Act.

\subsection{The Social Needs Fulfillment Scales}

The SPF-IL(s) consists of three social need scales and two physical need scales, each containing three items (Nieboer et al. 2005). For the study at hand we only use the three social need scales. The items of the affection scale are: (1) "Do people pay attention to you?"; (2) "Do people help you if you have a problem?"; (3) "Do you feel that people really love you?". The items of the scale for behavioral confirmation are: (1) "There are situations in which we deal with groups of people, for example at home, at work, or during our leisure time. Do others appreciate your role in the group?"; (2) "Do people find you reliable?"; (3) "Do you feel useful to others?". ${ }^{1}$ Finally, the items of the status scale are: (1) "Do people think you do better than others?"; (2) "Do people find you an influential person?"; (3) "Are you known for the things you have accomplished?". The scales are self-report, with each item having as answer categories 'never' (1), 'sometimes' (2), 'often' (3), and 'always' (4).

\subsection{Demographic Variables}

The demographic variables considered in this study were age, gender, and level of education. Age was measured as chronological age by year of birth, and level of education was measured in all samples (except sample 4) by 8 categories, ranging from no education at all (1) to university level (8). In sample 4 six categories were used, ranging from no education at all (1) to university level (6).

\subsection{Psychological Strengths}

For psychological strengths we had available the concepts of positive self-evaluation, hope, and self-management ability. The measure of positive self-evaluation in sample 3 was a self-constructed scale, containing eight items asking for a self-evaluation in comparison with age peers, of one's health, social life, financial situation, appearance, activities, contacts with family, achievements in life, and life attitude. A sample item is "What do you think of your social life, compared to your peers? Is it: (1) bad, (2) fair, (3) moderate, (4) good, (5) excellent?" The scale had a good internal consistency (Cronbach's alpha of .79). For measuring hope, we had available the Dutch translation of Snyder's Hope scale, consisting of eight items (Baneke 2001; Snyder et al. 1991). This scale measures Snyder's cognitive model of hope, which defines hope as "a positive motivational state that is based on a reciprocally derived sense of successful (a) agency (goal-directed determination), and (b) pathways (planning of ways to meet goals)" (Snyder et al. 1991, p. 570). A sample item is "I can think of many ways to get out of a jam: (1) definitely false, (2) mostly false, (3) mostly true, (4) definitely true". The scale has good psychometric properties (Snyder

\footnotetext{
1 The items of the scale for behavioral confirmation do not have exactly the same phrasing in all samples. In samples 2, 3 and 4 the first item is phrased as: "Do others appreciate the things you do?", and the second item as: "Do you feel that others find you reliable?". In sample 2 the third item is phrased as: "When you are with family, at school, work, church or club, do you feel that you belong to them?".
} 
et al. 1991) and showed a Cronbach's alpha of .82 in our sample 4. Finally, we measured self-management ability with the Self-Management Ability Scale (SMAS-30, Schuurmans et al. 2005), consisting of 30 items. The SMAS-30 measures overall self-regulatory capacity. A sample item is "How often do you take the initiative to get in touch with people who are dear to you? Is that: (1) never, (2) hardly ever, (3) sometimes, (4) often, (5) very often, (6) always". The scale has sound psychometric properties (Schuurmans et al. 2005), and the Cronbach's alphas in the studies at hand ranged from .89 to .91 .

\subsection{Loneliness}

In samples 4 and 5 we had available the original 11-items version of the widely used De Jong Gierveld loneliness scale (De Jong Gierveld and Kamphuis 1985), which is also being used as two subscales, one for emotional loneliness (6 items) and one for social loneliness (5 items) (Van Baarsen et al. 2001). A sample item of the scale for emotional loneliness is: "I miss having a really close friend"; a sample item of the scale for social loneliness is: "There is always someone that I can talk to about my day-to-day problems". Response options are (1) yes!, (2) yes, (3) more or less, (4) no, and (5) no!. The Cronbach's alphas of the overall scale and the two subscales ranged from .69 to .87 across the two samples.

\subsection{Indicators of Subjective Well-Being}

We distinguish three types of subjective well-being here: life satisfaction, positive affect, and negative affect. These three are generally accepted as separable and distinct types of subjective well-being (e.g., Lucas et al. 1996; Diener et al. 1999). As measures of overall life satisfaction we had available (in all samples except sample 2) Cantril's Ladder (Cantril 1965) or the Satisfaction With Life Scale (SWLS_-Diener et al. 1985). Cantril's Ladder asks one question: "Please imagine a ladder with steps numbered from zero at the bottom to ten at the top. Suppose we say that the top of the ladder represents the best possible life for you and the bottom of the ladder represents the worst possible life for you. If the top step is 10 and the bottom step is 0 , on which step of the ladder do you feel you personally stand at the present time?". The SWLS contains 5 items, such as "In most ways my life is close to my ideal: (1) strongly disagree, (2) disagree, (3) slightly disagree, (4) neither agree nor disagree, (5) slightly agree, (6) agree, (7) strongly agree”. Both are widely used scales. The SWLS showed good internal consistency in our samples, ranging from .81 to .87 .

For positive affect (PA) and negative affect (NA), we had available (in all samples except sample 3) the widely used PANAS (Watson et al. 1988). Both scales ask respondents to indicate to what extent they have experienced, over the past week, feelings and emotions like: "Interested" (PA) or "Distressed" (NA). Answer categories are (1) very slightly or not at all, (2) a little, (3) moderately, (4) quite a bit, and (5) extremely. The two 10-items scales had good properties, with Cronbach's alphas ranging from .79 to .85 (PA) and from .84 to .86 (NA). All scales used for well-being indicators have been translated in Dutch and are being used since long (Arrindell et al. 1999; Peeters et al. 1996).

\subsection{Analyses}

To test hypotheses 1 and $2 \mathrm{a}$, we investigated the factor structures across the five samples, and across six different age groups of sample 2. Sample 2 is large enough to allow 
composing six separate age groups, with still a substantial number of cases. The groups were composed of people aged 18-30, 30-40, 40-50, 50-60, 60-70, and 70-90. For each social need [each subscale of the SPF-IL(s)], a latent variable was hypothesized, with three observed variables loading on it. Because the three social needs are derived from theory and because we have multiple groups, we apply multigroup confirmatory factor analysis (MGCFA; using STATA 12). MGCFA is widely used for testing the stability of factor structures (measurement invariance), by setting cross-group constraints and comparing more restricted with less restricted models (e.g., Byrne et al. 1989; Jöreskog 1971; Steinmetz et al. 2009). The models were tested using maximum-likelihood estimation; missing values were treated by list-wise deletion. First, configural invariance was tested by an unconstrained model. Next, increasingly constrained models were tested by setting measurement loadings, measurement intercepts, and measurement residuals to be equal respectively (and cumulatively). The subsequent models examine metric invariance, strong invariance, and strict invariance. The Comparative fit index (CFI), Tucker-Lewis index (TLI), Akaike information criterion (AIC), and the root-mean-square error of approximation (RMSEA) were used to evaluate model fit (Schreiber et al. 2006). Although the Chi square test has been demonstrated to be inappropriate for sample sizes of 400 or more (Kenny 2011), as is the case with most of our (sub)samples, it will be presented for illustration.

Regarding the comparison of the three social need fulfilments by gender, we applied Multivariate Analysis of Variance (MANOVA), which is used to test differences between groups (gender) across several dependent variables (the three needs) simultaneously. Furthermore, we investigated the correlations between each of the three social need fulfillment scales and the various concepts that are expected to relate to the social needs according to our hypotheses. We computed zero-order correlations and partial correlations. Zeroorder correlations show the simple correlations of each of the social needs with the different indicators. However, for testing the hypotheses concerning the unique association of a specific social need with an indicator, we need to look at the correlations that control for the effects of the other two social needs. The sizes of the partial correlation coefficients were compared using Steiger's $z$ tests (Steiger 1980). Finally, we executed linear regression analyses in SPSS version 25, using the macro PROCESS of Hayes (2013), to explore the psychological strengths that we considered as possible mediations (each as mediator $\mathrm{M})$ between the three social need fulfilments as independent variables (X), and each of the well-being outcomes, including loneliness, as dependent variables (Y). PROCESS estimates the indirect effect and applies bootstrapping to estimate its $95 \%$ confidence interval. The mediation effect is considered statistically significant when the $95 \%$ confidence interval does not include zero.

\section{Results}

\subsection{Factor Structures and Internal Consistency}

Table 2 shows the results of the MGCFA, testing the first hypothesis, expecting that the three social need scales would show robustness in the five different samples (upper part of Table 2). Due to the large population in sample 2, we also made six age groups of this sample, in order to test our expectation also in these subpopulations. The lower part of Table 2 shows the results for these six age groups. 
Table 2 Multigroup confirmatory factor analysis for the three social needs: factor structure between the five samples and six age groups of sample 2

\begin{tabular}{llllllll}
\hline Model & $\chi^{2}$ & Df & RMSEA & $90 \%$ CI & CFI & TLI & AIC \\
\hline Five samples (N=14,588) & & & & & & & \\
Configural invariance & 2513.006 & 123 & .082 & $.079, .084$ & .941 & .914 & $217,409.912$ \\
Metric invariance & 2822.133 & 147 & .079 & $.076, .083$ & .934 & .919 & $217,671.039$ \\
Strong invariance & $\mathbf{1 6 2 5 . 9 8 6}$ & $\mathbf{1 6 8}$ & $\mathbf{. 0 5 5}$ & $\mathbf{. 0 5 2 , . 0 5 7}$ & $\mathbf{. 9 6 4}$ & $\mathbf{. 9 6 1}$ & $\mathbf{2 1 6 , 4 3 2 . 8 9 2}$ \\
Strict invariance & 3522.045 & 204 & .075 & $.073, .077$ & .918 & .928 & $218,256.951$ \\
Six age groups (N=12,559) & & & & & & & \\
Configural invariance & 1381.125 & 147 & .063 & $.060, .066$ & .967 & .951 & $182,036.286$ \\
Metric invariance & 1494.868 & 177 & .060 & $.057, .062$ & .964 & .957 & $182,090.028$ \\
Strong invariance & $\mathbf{8 0 2 . 4 5 4}$ & $\mathbf{2 0 4}$ & $\mathbf{. 0 3 7}$ & $\mathbf{. 0 3 5 , . 0 4 0}$ & $\mathbf{. 9 8 4}$ & $\mathbf{. 9 8 3}$ & $\mathbf{1 8 1 , 3 4 3 . 6 1 4}$ \\
Strict invariance & 1371.636 & 249 & .046 & $.044, .049$ & .970 & .974 & $181,822.797$ \\
\hline
\end{tabular}

The best fitting model is indicated in bold. RMSEA root-mean-square error of approximation, $C I$ confidence interval, CFI comparative fit index, TLI Tucker-Lewis index, AIC Akaike information criterion. Criteria for interpreting model fit are: RMSEA $<.06$ for good fit and RMSEA $<.08$ for reasonable fit; CFI $\geq .95$ for acceptance; TLI $\geq .95$, can be $0>\mathrm{TLI}>1$ for acceptance; AIC the smallest value indicates the best fitting model (Schreiber et al. 2006)

Because, according to Kenny (2011), the RMSEA is currently the most widely used measure of model fit, and seems to be the only fit index among 20 alternatives that was unaffected by model complexity (Cheung and Rensvold 2002), we focus on the RMSEA, and use the other fit indices to add to the best model fit.

The results support configural invariance of the three social need fulfilments across the five samples based on an RMSEA value of $.082(90 \% \mathrm{CI}=.079, .084)$, which is close to the frequently established criterion of $<.08$ for reasonable model fit (Hu and Bentler 1999). This result suggests that the same model structure exists in all five samples. The subsequent test of metric invariance was also supported $(\mathrm{RMSEA}=.079,90 \% \mathrm{CI}=.076, .083)$, suggesting that the SPF-IL(s) subscales measure the social needs similarly (i.e., a similar metric) between groups. The RMSEA value for strong invariance suggests good fit (.055; $90 \% \mathrm{CI}=.052, .057)$, based on the guidelines suggested by Browne and Cudeck (1993; i.e., RMSEA <.06). This result suggests there are no differences between groups in the means of the three SPF-IL(s) social need subscales. Finally, the test of strict invariance demonstrated reasonable fit $(\mathrm{RMSEA}=.075 ; 90 \% \mathrm{CI}=.073, .077)$, suggesting similar reliabilities of SPF-IL(s) social need subscale scores between groups. Thus, it can be concluded that all models show reasonable to good fit in terms of the RMSEA, while, taking also the other fit indices and their criteria into account, the model of strong invariance shows to be the best fitting model for the five samples.

The six age groups of sample 2 show generally comparable results. The test of configural invariance demonstrated reasonable fit $(\mathrm{RMSEA}=.063 ; 90 \% \mathrm{CI}=.060, .066)$. The tests of metric invariance (RMSEA $=.060 ; 90 \% \mathrm{CI}=.057, .062$ ), strong invariance $(\mathrm{RMSEA}=.037 ; 90 \% \mathrm{CI}=.035, .040)$, and strict invariance (RMSEA $=.046 ; 90 \%$ $\mathrm{CI}=.044, .049)$ all showed good fit. Also the other fit indices show acceptable fit, for all types of invariance, while also the model of strong invariance appears to be the best fitting model.

Taken together, these results provide support for the similarity of the SPF-IL(s) social needs factor structure, subscale metrics, mean scores, and reliabilities across the five 


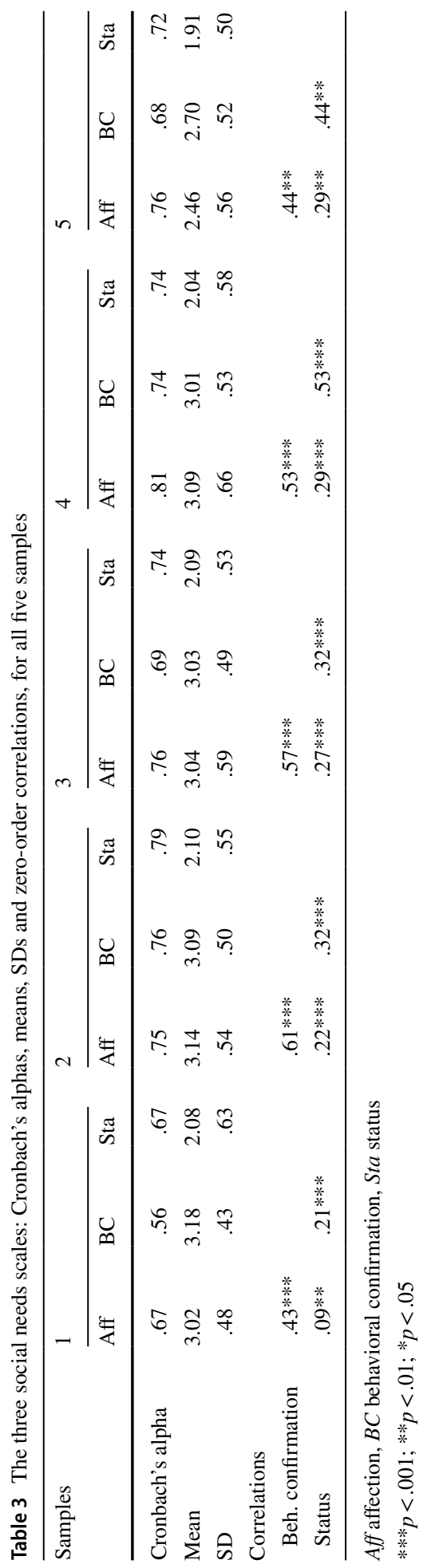


samples and the six age groups of sample 2. Table 3 shows the Cronbach's alphas, the means and standard deviations, as well as the inter-correlations of the three social need scales, for each of the five samples.

Most samples show acceptable or good Cronbach's alphas, although the alphas in sample 1 are rather low. All samples, except the single 52+women in sample 5, show comparable Means and SDs. Overall, in each of the samples, the mean scores on the affection and behavioral confirmation scales are higher than the mean score on the status scale, with affection in general still somewhat higher than behavioral confirmation. This may reflect the different ease of satiation discussed above (Nieboer and Lindenberg 2002). Still, these findings indicate that there is a general pattern of how much on average the social needs are being fulfilled. Not surprisingly, the single women in sample 5 show a somewhat different pattern. This sample consisted of widowed and divorced or single women aged 52 and older who signed up to take part in an intervention study on improvement of selfmanagement ability, well-being and loneliness (Kremers et al. 2006). As one might expect, these women scored relatively low on affection and also somewhat lower on behavioral confirmation and status than the average in other samples.

The correlations between the three social needs show, overall, that affection and behavioral confirmation correlate relatively strongly (between .43 and .61), whereas status correlates lower with behavioral confirmation (between .21 and .53) and still lower with affection (between .09 and .29).

We also examined the Cronbach's alphas for the six separate age groups within Sample 2. The analyses yielded results (not shown in Table) that are highly comparable to those of the other samples. In all age groups the Cronbach's alphas ranged from .69 to .76 for affection; from .73 to .79 for behavioral confirmation; and from .78 to .80 for status. From these results, together with the results shown in Table 2, it can be concluded that, as expected in $\mathrm{H} 1$, the stability and reliability of the three separate social need scales are robust (in all five samples, and in all age groups of sample 2).

\subsection{Associations with Age, Gender and Education}

Table 4 shows, first of all, the zero-order and partial correlations of the three social needs with age, gender, and education, for each of the five samples. Also the correlations with all other concepts are shown in Table 4, and will be discussed consecutively in the following sections. Note that not all indicators were measured in all samples. Therefore, some of the cells in Table 4 remain empty.

Regarding age, we overall found relatively low correlations, and a rather inconsistent pattern across the various social needs and the various samples, indicating no support for H2a. Regarding gender, Table 4 indicates the expected differences between men and women, which we further tested using MANOVA. The results showed, as expected in $\mathrm{H} 2 \mathrm{~b}$, that -in all samples (except sample 5 which contains only women) the three social need fulfilments differ significantly for men and women (Sample 1: Wilks' $\lambda=.925, F(3$, $983)=26.734, p<.001, \eta^{2}=.075$; Sample 2: Wilks' $\lambda=.925, F(3,12,555)=337.021$, $p<.001, \eta^{2}=.075$; Sample 3: Wilks' $\lambda=.933, F(3,430)=10.320, p<.001, \eta^{2}=.067$; Sample 4: Wilks' $\left.\lambda=.952, F(3,358)=5.990, p<.01, \eta^{2}=.048\right)$. In addition, the univariate tests (between-subjects) showed that-in all four samples-women have higher scores on affection need fulfillment than men (Sample 1: $F=6.94, p<.01$; Sample 2: $F=86.04, p<.001$; Sample 3: $F=14.89, p<.001$; Sample 4: $F=6.51, p<.05)$. Men have higher scores on status need fulfillment than women (Sample 1: $F=66.81$, 


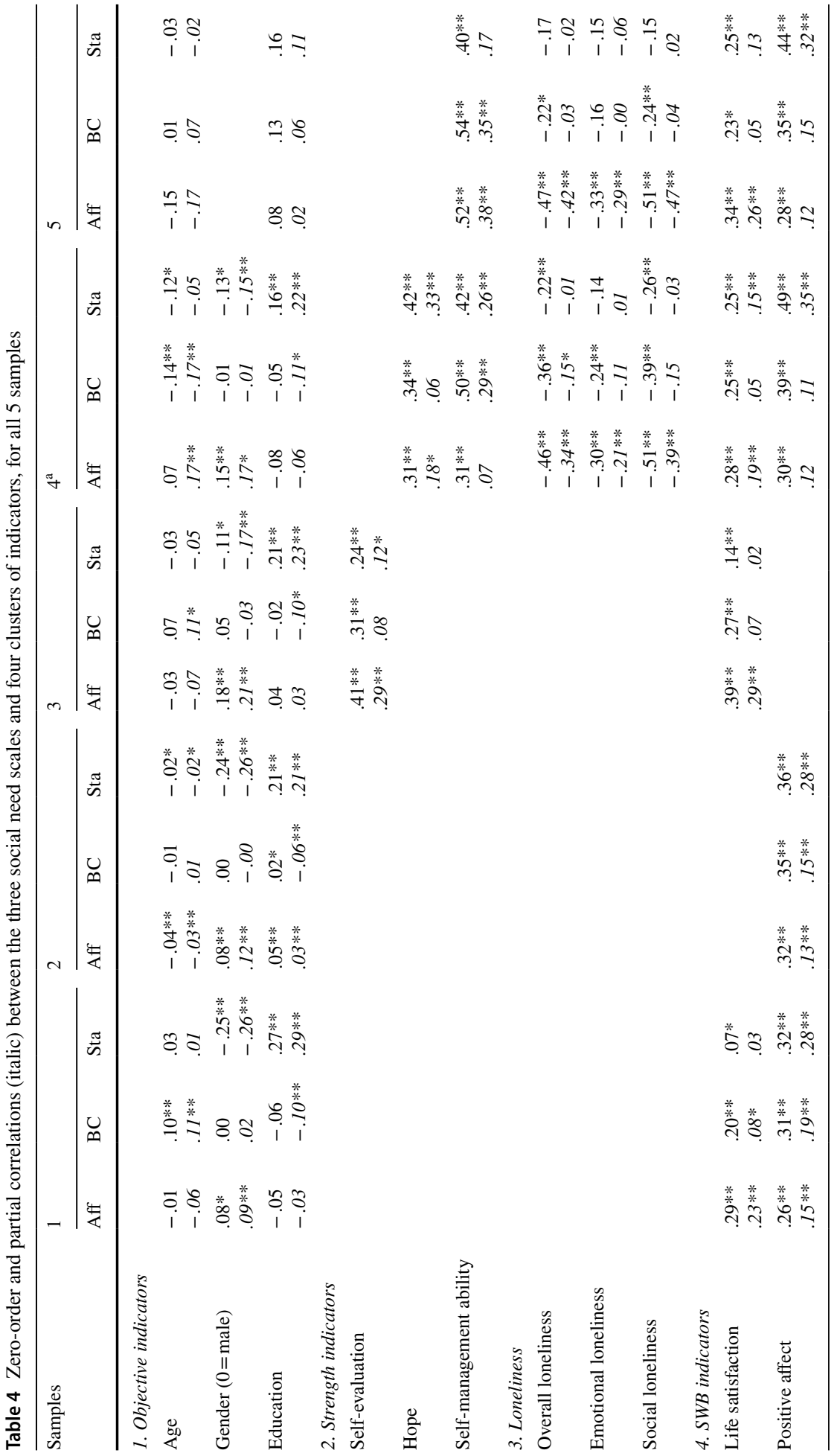




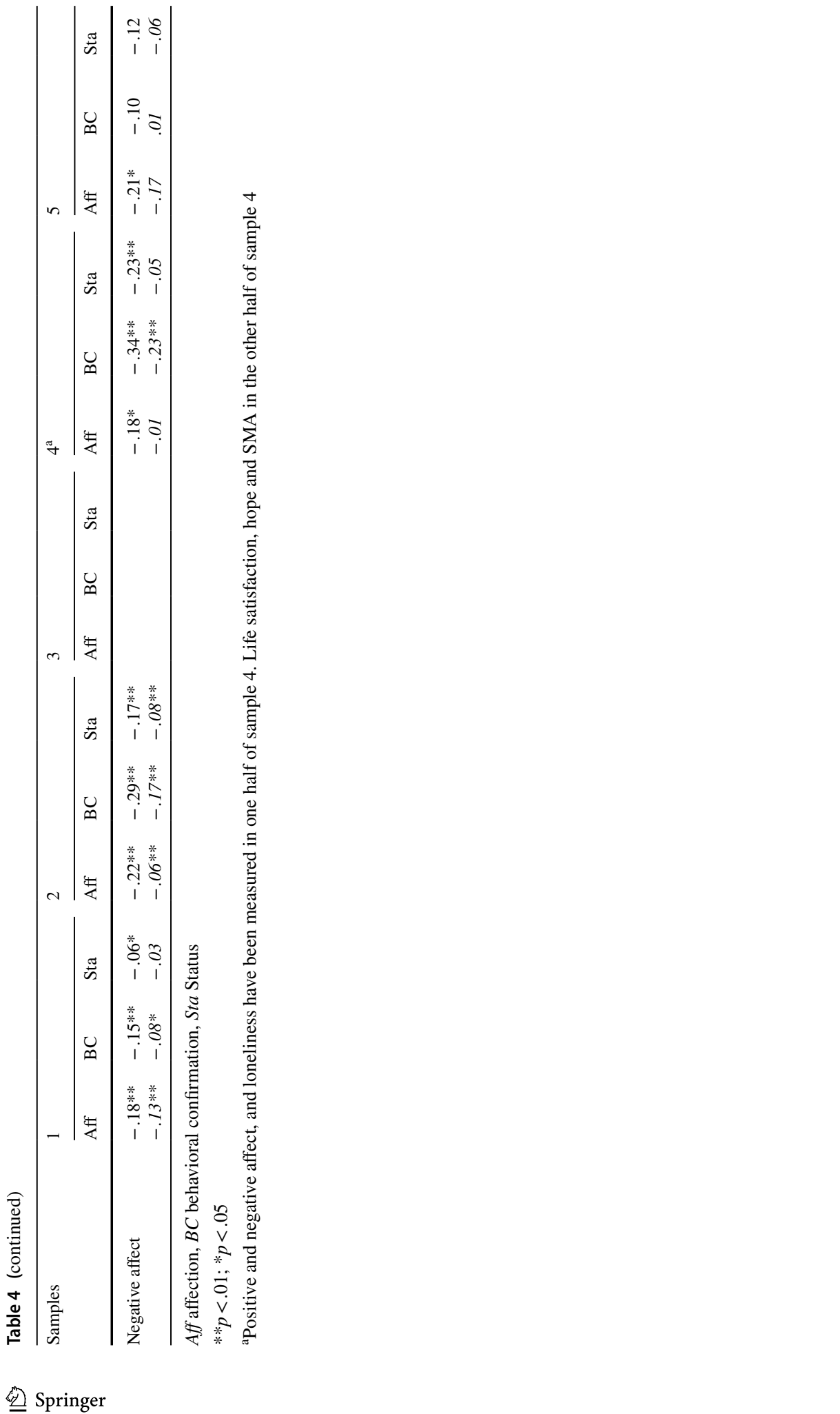


$p<.001$; Sample 2: $F=742.20, p<.001 ;$ Sample 3: $F=6.97, p<.01$; Sample 4: $F=5.67, p<.05)$. Moreover, men and women did not differ on the fulfillment of the need for behavioral confirmation in any of the samples (Sample 1: $F=.02, p=.89$; Sample 2: $F=.03, p=.86$; Sample 3: $F=1.31, p=.25$; Sample 4: $F=.27, p=.61$ ).

Regarding education, we found, as expected in $\mathrm{H} 2 \mathrm{c}$, that the correlations with status need fulfilment are positive and significantly stronger than the correlations with behavioral confirmation. The correlation with affection is very low or non-existent. This we found in samples 1-4 (Steiger $z$ tests, each comparing the partial correlations of two social needs: Sample 1: $z_{\mathrm{BC}-\mathrm{Sta}}=-10.07, p<.001$; Sample 2: $z_{\mathrm{Aff}-\mathrm{BC}}=11.55$, $p<.001, z_{\mathrm{BC}-\mathrm{Sta}}=-26.46, p<.001$; Sample 3: $z_{\mathrm{BC}-\mathrm{Sta}}=-6.02, p<.001$; Sample 4: $z_{\mathrm{BC}-\mathrm{Sta}}=-5.59, p<.001$ ). In sample 5 (single women, age $52+$ ) none of the correlations between education and the three needs are significant, although status seems somewhat stronger than the other two needs. H2c is thus largely confirmed.

\subsection{Psychological Strengths}

It was expected (H3) that all three social needs relate positively to positive self-evaluation, hope, and self-management ability. For self-evaluation (Sample 3) it was found that it relates significantly to affection and status and, significantly more strongly to affection than to status $\left(z_{\mathrm{Aff}-\mathrm{Sta}}=3.04, p<.001\right)$. For hope (Sample 4$)$ also significant associations with affection and status were found, but here the association with status is significantly stronger than that with affection $\left(z_{\text {Aff-Sta }}=-2.194, p<.05\right)$. Regarding self-management ability, Sample 4 showed no association with affection, and relatively strong and comparable associations with both behavioral confirmation and status $\left(z_{\mathrm{BC}-\mathrm{Sta}}=1.85, p=.07\right)$. Results for sample 5 (single women, age 52+) are different. Here we find relatively strong and comparable associations for both affection and behavioral confirmation, $\left(z_{\text {Aff-BC }}=0.36, p=.36\right)$, not status. It is concluded that $\mathrm{H} 3$ is only partially supported, as not all three social needs are related to all three psychological strengths simultaneously.

\subsection{Loneliness}

For loneliness we expected (negative) associations with affection and behavioral confirmation and no associations with status (H4a). Indeed, neither for overall loneliness, nor for emotional and social loneliness, we found status to play a role (see samples 4 and 5). Overall loneliness was most associated with affection, although behavioral confirmation also showed a significant association in Sample 4, but significantly smaller than affection $\left(z_{\text {Aff-BC }}=4.88, p<.001\right)$. We also expected $(\mathrm{H} 4 \mathrm{~b})$ affection to relate most to emotional loneliness, and behavioral confirmation most to social loneliness. However, this we did not find. Affection, as compared to behavioral confirmation, has the strongest association with both emotional and social loneliness in both samples 4 and 5 . Moreover, the negative associations of affection with social loneliness seem to be even stronger in both samples than the associations of affection with emotional loneliness (Sample 4: -.39 vs. -.21 ; Sample 5: -.47 vs. -.29 ). So, the expected stronger association of behavioral confirmation need fulfilment with social loneliness is not found. Thus, H4a is confirmed, but H4b is only partially confirmed. 


\subsection{Indicators of Subjective Well-Being}

Regarding life satisfaction we found that affection need fulfillment, as expected in H5a, has the strongest correlation. This was found in three of the four samples that contained life satisfaction (Samples 1, 3 and 5). In Samples 3 and 5, only affection showed significant associations with life satisfaction, whereas in sample 1, also a significant association was found for behavioral confirmation, although significantly smaller than that for affection $\left(z_{\mathrm{Aff}-\mathrm{BC}}=4.68, p<.001\right)$. In sample 4 we found, contrary to expectation, also a significant association with status, which was comparably as strong as the association with affection $\left(z_{\text {Aff-Sta }}=0.16, p=87\right)$.

With respect to positive affect (PA), it was found that all three needs correlated significantly with PA in samples 1 and 2, with, as expected, status showing the strongest association of the three needs (Sample 1: $z_{\text {Sta-BC }}=-2.35, p<.05 ; z_{\text {Sta-Aff }}=-3.16, p<.01$. Sample 2: $\left.z_{\text {Sta-BC }}=-13.97, p<.001 ; z_{\text {Sta-Aff }}=-13.95, p<.001\right)$. In samples 4 and 5 , only status correlated significantly with positive affect. H5a is thus largely confirmed.

Regarding negative affect (NA), we expected the need for behavioral confirmation to have the strongest association with NA (H5b). As can be seen in Table 4, we found in samples 2 and 4 behavioral confirmation need fulfilment to have indeed a stronger association with NA than the other two needs (Sample 2: $z_{\mathrm{Aff}-\mathrm{BC}}=14.23, p<.001 ; z_{\mathrm{BC}-\mathrm{Sta}}=-8.79$, $p<.001)$. However, in sample 1 affection has the strongest association with NA even though it is not significantly different from the association with behavioral confirmation $\left(z_{\mathrm{Aff}-\mathrm{BC}}=-1.54, p=.12\right)$. Finally, although affection seems to have the strongest association with negative affect in sample 5, none of the correlations in sample 5 reach significance. H5b is thus only partly supported.

\subsection{Possible Mechanisms}

Finally, some mechanisms were explored, focusing on the possible mediating role of psychological strengths in the link between social need fulfillments and indicators of wellbeing, including loneliness. For this we had available in samples 3, 4 and 5 (not in samples 1 and 2) one or more of the psychological strengths (as mediators) and one or more of the indicators of well-being, including loneliness, as dependent variables. As shown in Table 4, it was found that one or more of the three social need fulfilments relate to the three psychological strengths considered in this study, and that one or more of the three social needs relate significantly to the well-being outcomes, including loneliness, except for negative affect in sample 5. Also, all psychological strengths related to one or more of the wellbeing outcomes: positive self-evaluation (sample 3) was found to correlate significantly with life satisfaction $(r=.63, p<.001)$, as did hope in sample $4(r=.55, p<.001)$. Selfmanagement ability was found to relate significantly to life satisfaction, both in sample 4 $(r=.30, p<.001)$, and in sample $5(r=.55, p<.001)$. Moreover, self-management ability was found to relate to positive affect $(r=.59, p<.001)$, and loneliness $(r=-.48, p<.001)$ in sample 5 , as well as to negative affect $(r=-.19, p<.05)$, but no associations were found for the three social needs with negative affect in this sample. In Table 5 the results of the mediational analyses are shown.

For each dependent variable and each mediator, we executed separate regression analyses, using the macro PROCESS (Hayes 2013) to estimate the indirect effect $(a b)$ of the mediator between the three social needs as independent variables $(X)$, and each one of the 


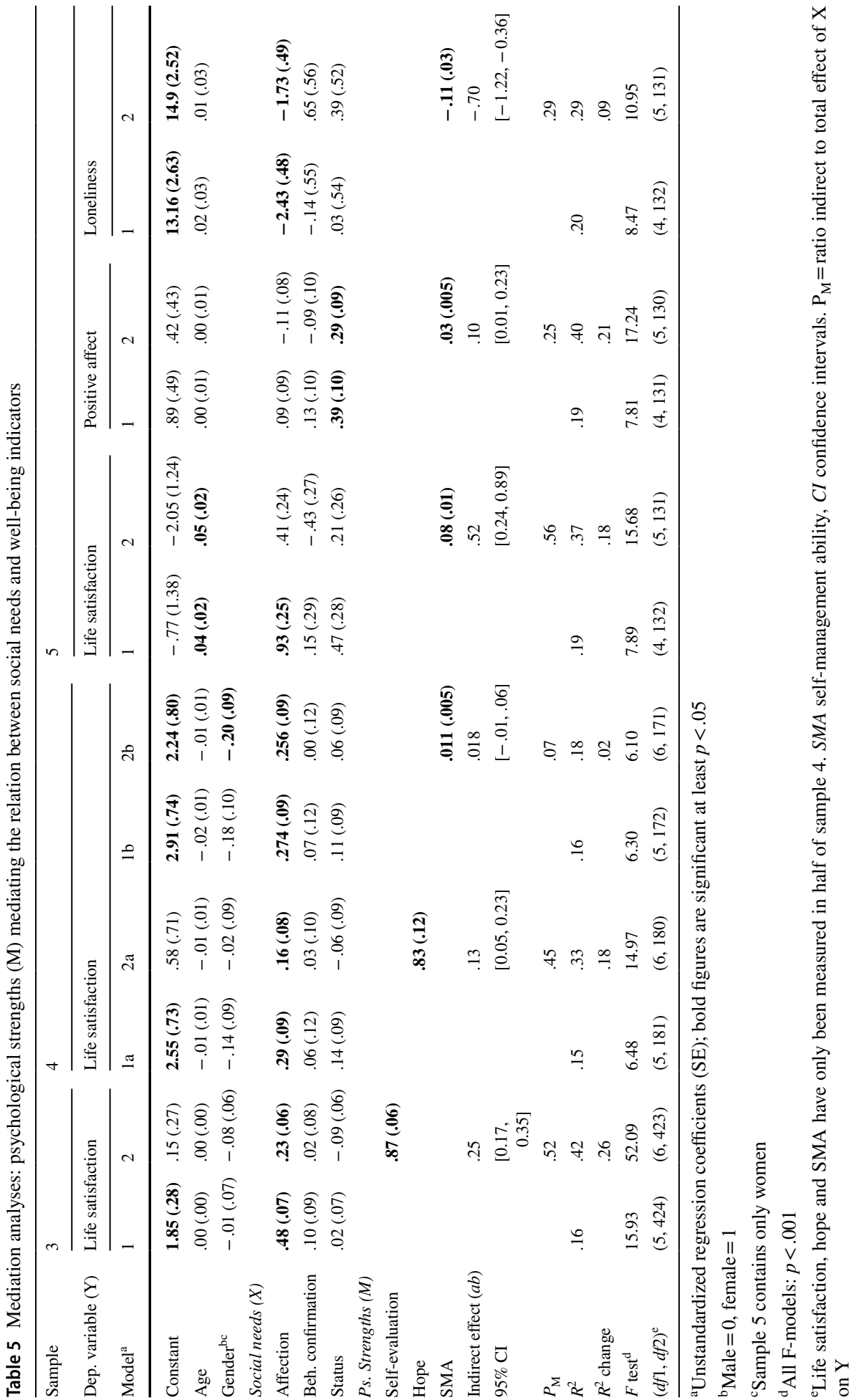


indicators of well-being, including loneliness, as dependent variable $(Y)$. Age and gender were used as controls.

Regarding positive self-evaluation (sample 3), there was a significant mediation effect of self-evaluation on the link between affection need fulfilment and life satisfaction $(a b=.25$, $95 \%$ CI $[0.17,0.35])$, the mediator accounting for $52 \%$ of the total effect $\left(P_{\mathrm{M}}=.52\right)$. Also hope was found to mediate the association between affection and life satisfaction $(a b=.13$, $95 \%$ CI $[.05, .23]$, accounting for almost half of the total effect $\left(P_{\mathrm{M}}=.45\right)$. Self-management ability in sample 4 did not mediate the link between affection and life satisfaction $(a b=.02,95 \%$ CI $[-0.01,0.06])$. Yet, in sample 5, self-management ability significantly mediated the link between affection need fulfilment and life satisfaction $(a b=.52,95 \%$ CI $[0.24,0.89])$, the mediator accounting for more than half of the total effect $\left(P_{\mathrm{M}}=.56\right)$. Additionally, self-management ability weakly mediated the link between status need fulfilment on positive affect $(a b=.10,95 \%$ CI $[.01, .23])$, the mediator accounting for $25 \%$ of the total effect $\left(P_{\mathrm{M}}=.25\right)$. Finally, a significant mediation effect of self-management ability on the link between affection need fulfilment on loneliness was found $(a b=-.70,95 \% \mathrm{CI}$ $[-1.22,-.36])$, the mediator accounting for almost one-third of the total effect $\left(P_{\mathrm{M}}=.29\right)$.

It is concluded that there are significant mediation effects of all psychological strengths considered in our study (self-evaluation, hope and self-management ability) on the links between affection need fulfilment and life satisfaction as well as loneliness. For status need fulfilment, self-management ability was only a weak (though significant) mediator for the link with positive affect. No mediating effects of psychological strengths were found for the links between behavioral confirmation need fulfilment and well-being indicators.

\section{Discussion}

The fulfilment of social needs is essential for human beings to function well and thrive (cf. Deci and Ryan 2000). However, so far, there is a lack of more in-depth knowledge about which social needs are indeed important for which types of well-functioning. Curiously, the very question whether fulfilling a certain social need is more beneficial for certain indicators of well-functioning than fulfilling other social needs has rarely come up in the literature. This may be mainly due to the fact that social needs are often lumped together under one overall need to belong, or one overall need for relatedness. However, even studies (such as Tay and Diener 2011) that do differentiate between social needs and trace their associations with different types of subjective well-being (life satisfaction, positive and negative affect), do not problematize the possible differential role specific social need fulfillments may play for specific indicators of well-functioning.

What is needed is a deeper theoretical and empirical understanding of the role of social relationships and other social provisions for well-being and thriving. If specific social need fulfilments make separable contributions to different indicators of well-functioning, then it is important to focus on the different social satisfiers of social needs (i.e. the different kinds of social relationships, social activities, and social situations) and how they relate to indicators of well-functioning. SPF theory distinguishes three social needs and measures them in terms of the different social satisfiers. Applying SPF theory, we were able to link the different social need fulfilments to their associations with various indicators of well-functioning (psychological strengths, life satisfaction, and positive affect, and absence of loneliness and negative affect). Moreover, we explored possible mechanisms through which social need fulfilments may relate to subjective well-being. The empirical study in 
which we investigated these links and mechanisms was based on five different samples, including one very large sample of over 13,000 people.

The results showed, first of all, that social needs should indeed not be lumped together in one overall need to belong or need for relatedness. The needs for affection, behavioral confirmation, and status can be clearly distinguished, providing support for the robustness of the factor structure and internal consistencies of the three social needs across the five samples, as well as across age groups covering the whole adult life span. Second, for the demographic variables, both the hypotheses on gender and level of education were supported, but not on age. As expected, women in all samples scored significantly higher on levels of affection need fulfillment than men, whereas men scored significantly higher on levels of status need fulfillment than women. No gender differences were found for behavioral confirmation need fulfillment, as expected. The associations for education were largely as expected: higher education was significantly stronger associated with status need fulfillment as compared to the other two needs, in 4 of the 5 samples. Thus, differences in gender and education also systematically affect the level of need fulfilment with regard to status and affection. However, for age we found relatively weak correlations, and rather inconsistent patterns over the various samples. Possibly the fulfilments of social needs follow complex patterns with age, requiring more in-depth investigation in future studies.

Third, the psychological strength indicators that we examined (i.e., self-evaluation, hope, and self-regulatory capacity), showed as expected that all three social need fulfillments have clear and quite strong associations with these indicators, even though the partial correlations show that in some sample a particular need is more highly correlated with a particular indicator than in another sample. These findings do support the conjecture that all three social need fulfilments contribute to psychological strengths.

Fourth, it was found that for loneliness, as expected, status did not play a significant role. However, contrary to expectation, social loneliness was not most strongly (negatively) associated with behavioral confirmation. Rather, both emotional and social loneliness were most strongly associated with affection need fulfillment. Although there is evidence for the bidimensionality of the Jong Gierveld loneliness scale (Van Baarsen et al. 2001), our results suggest that even social loneliness taps more into lack of affection than into lack of behavioral confirmation need fulfillment.

Fifth, concerning the three indicators of subjective well-being, it was found, as expected, that affection need fulfillment related the strongest to life satisfaction, and status need fulfillment the strongest to positive affect. These results are in line with the findings of $\mathrm{Ng}$ and Diener (2014), Nieboer et al. (2005), Steverink and Lindenberg (2006), and Tay and Diener (2011), who also showed comparable findings on the association between the need for respect (status) and positive feelings. The overall results for negative affect are less clear cut, since the expected stronger association of behavioral confirmation need fulfillment with negative affect was only found in two of the four samples that contained negative affect. Tay and Diener (2011) also found a more diverse pattern in need fulfillments for negative affect than for positive affect. It can be concluded that the fulfilments of the three social needs cannot be clearly differentiated for their associations with psychological strengths, but they are quite differentially associated with important indicators of subjective well-being.

With regard to the possible mediating role of psychological strengths in the link between social need fulfillments and indicators of well-being, including loneliness, we found that all three psychological strengths play a significant role. Self-evaluation, hope, and self-management ability all (partially) mediated the link between affection and life satisfaction, as well as the link between affection and loneliness. Thus, with regard to the 
impact of psychological strengths on well-being, it is the combination with affection need fulfilment that seems to be most important. Self-management ability was also found to play a role in the link between status need fulfilment and positive affect. We did not find any mediating role of the three psychological strength for the link between social needs fulfilment and negative affect. We can conclude that social needs fulfillment has both direct and indirect effects on well-being, and that psychological strengths, besides being important in themselves, play a sizable mediating role between social needs fulfillment and indicators of well-being.

The study also has some limitations. First of all, although the various samples allowed the testing of the scales in different age groups and across gender, all samples only contained cross-sectional data, which do not allow us to draw conclusions about changes in the different social needs over time, nor about the presumed causal paths from social need fulfillment to positive functioning. Clearly, it is likely that the causal paths will be bidirectional. For example, self-regulatory capacity and positive affect are likely to contribute to achieving higher levels of social need fulfilment. Social needs are thus at the center of recursive loops that connect social need fulfillments to positive outcomes and vice versa. Still, the purpose of this study was not to trace changes over time but to answer the question whether different social needs could robustly be distinguished in their expected joint and specific associations with various indicators of well-functioning. Second, none of the samples contained all of the variables of positive functioning that may be relevant for assessing their associations with the three social need fulfilments. Future studies may explicitly theorize about how the three social needs would relate to specific indicators of well-functioning, including specifying mechanisms, and test the hypothesized associations and mechanisms in samples and designs specifically set up for that purpose. Third, this study investigated people's social needs only, while according to SPF theory two physical needs (comfort and stimulation) are just as important. However, the focus and scope of this paper were on the social needs. Future research might fruitfully include the physical needs as well. Fourth, even though we had the advantage of a very large sample (sample 2), our study contained only Dutch samples. Although we have no reason to assume that the Dutch differ from other Western-European populations, and the SPF-ILs scale has been reliably used in, for example, South African (Cramm et al. 2014) and African American (Tiernan et al. 2014) populations, future research should include countries across the world, as Tay and Diener (2011) and Ng and Diener (2014) have done in their studies.

Despite these limitations, the study made some important contributions. The first is that it is one of the first to throw more light on the question whether different social need fulfillments have different associations to different psychological strengths, loneliness, and subjective well-being outcomes. An important implication of this finding is that it shows the importance of looking differentially at social 'satisfiers' (i.e., the different kinds of social relationships, social activities, and social situations), because they fulfill different social needs. Thus, the importance of different kinds of social relationships as satisfiers of different social needs comes into focal attention.

The second important contribution is that it points to the importance of looking deeper into the mechanisms that may explain why social need fulfilments are so important to wellfunctioning. One of the important mechanisms may be that social need fulfilments add to the development of psychological strengths, which, besides being important in themselves, also contribute to subjective well-being. For the design of interventions and policy directed at the improvement of well-being of individuals, this is important knowledge. If social structures and institutions could provide better opportunities for people to fulfill their 
various social needs, this would add to their overall well-being, also through improvement of psychological strengths.

Finally, this knowledge may also help individuals themselves to become more aware of their different social needs and conditions of need fulfillment. For example, for loneliness, being accepted in a group is likely to have less effect than receiving affection from a partner or friend. Awareness of the conditions of social needs fulfilment may also contribute to the development of psychological strengths, which, in turn, may contribute to better 'social health behavior', analogous to 'physical health behavior'. We can conclude that if each of the social needs makes separable contributions, then a mix of social satisfiers (different kinds of social relationships, social activities and social situations) is required for social needs fulfilment and thus for human well-functioning and thriving.

Acknowledgements Funding was provided by Nederlandse Organisatie voor Wetenschappelijk Onderzoek (Grant No. 510-05-0101), ZonMw (Grant No. 014-91-046) and Fonds Sluyterman van Loo (Grant No. SvL/ jn subs eenz 077).

\section{Compliance with Ethical Standards}

Conflict of interest All authors declare that they have no conflict of interest.

Open Access This article is distributed under the terms of the Creative Commons Attribution 4.0 International License (http://creativecommons.org/licenses/by/4.0/), which permits unrestricted use, distribution, and reproduction in any medium, provided you give appropriate credit to the original author(s) and the source, provide a link to the Creative Commons license, and indicate if changes were made.

\section{References}

Anderson, C., Hildreth, J. A. D., \& Howland, L. (2015). Is the desire for status a fundamental human motive? A review of the empirical literature. Psychological Bulletin, 141, 574-601.

Arrindell, W. A., Heesink, J., \& Feij, J. A. (1999). The Satisfaction With Life Scale (SWLS): Appraisal with 1700 healthy young adults in the Netherlands. Personality and Individual Differences, 26, 815-826.

Baneke, J. J. (2001). Vragenlijst voor persoonlijke doelen en ervaringen; Nederlandse vertaling Snyder's hope scale. Enschede, NL: Unpublished manuscript.

Baumeister, R. F., DeWall, C. N., Ciarocco, N. J., \& Twenge, J. M. (2005). Social exclusion impairs self-regulation. Journal of Personality and Social Psychology, 88, 589-604. https://doi. org/10.1037/0022-3514.88.4.589.

Baumeister, R. F., \& Leary, M. R. (1995). The need to belong: Desire for interpersonal attachments as a fundamental human motivation. Psychological Bulletin, 117, 497-529.

Baumeister, R. F., \& Sommer, K. L. (1997). What do men want? Gender differences and two spheres of belongingness: Comment on Cross and Madson (1997). Psychological Bulletin, 122, 38-44.

Browne, M. W., \& Cudeck, R. (1993). Alternative ways of assessing model fit. In K. A. Bollen \& J. S. Long (Eds.), Testing structural equation models (pp. 136-162). Newbury Park, CA: Sage.

Byrne, B. M., Shavelson, R. J., \& Muthén, B. (1989). Testing for the equivalence of factor covariance and mean structures: The issue of partial measurement invariance. Psychological Bulletin, 105, 456-466.

Cacioppo, J., \& Patrick, W. (2010). Loneliness: Human nature and the need for social connection. New York: W.W. Norton.

Cantril, H. (1965). The patterns of human concern. New Brunswick, NJ: Rutgers University Press.

Cheung, G. W., \& Rensvold, R. B. (2002). Evaluating goodness-of-fit indexes for testing measurement invariance. Structural Equation Modeling, 9, 233-255.

Coan, J. A., \& Sbarra, D. A. (2015). Social baseline theory: The social regulation of risk and effort. Current Opinion in Psychology, 1, 87-91. https://doi.org/10.1016/j.copsyc.2014.12.021.

Cramm, J. M., \& Nieboer, A. P. (2015). Social cohesion and belonging predict the well-being of community dwelling older people. BMC Geriatrics, 15, 30. https://doi.org/10.1186/s12877-015-0027-y. 
Cramm, J. M., Nieboer, A. P., \& Lorenzo, T. (2014). Comparing education, employment, social support and well-being among youth with disabilities and their peers in South Africa. Applied Research in Quality of Life, 9, 517-524. https://doi.org/10.1007/s11482-013-9247-5.

De Jong Gierveld, J., \& Kamphuis, F. (1985). The development of a Rasch-type loneliness scale. Applied Psychological Measurement, 9, 289-299.

Deci, E. L., \& Ryan, R. M. (2000). The "what" and "why" of goal pursuits: Human needs and the selfdetermination of behavior. Psychological Inquiry, 11, 227-268.

Demir, M., \& Özdemir, M. (2010). Friendship, need satisfaction and happiness. Journal of Happiness Studies, 11, 243-259.

Diener, E., Emmons, R. A., Larson, R. J., \& Griffin, S. (1985). The satisfaction with life scale. Journal of Personality Assessment, 49, 71-75.

Diener, E., Ng, W., Harter, J., \& Arora, R. (2010). Wealth and happiness across the world: Material prosperity predicts life evaluation, whereas psychosocial prosperity predicts positive feeling. Journal of Personality and Social Psychology, 99, 52-61.

Diener, E., Suh, E. M., Lucas, R. E., \& Smith, H. L. (1999). Subjective well-being: Three decades of progress. Psychological Bulletin, 125, 276-302.

Eisenberger, N. I., Lieberman, M. D., \& Williams, K. D. (2003). Does rejection hurt? An fMRI study of social exclusion. Science, 302, 290-292. https://doi.org/10.1126/science.1089134.

Frieswijk, N., Steverink, N., Buunk, B. P., \& Slaets, J. P. J. (2006). The effectiveness of a bibliotherapy in increasing the self-management ability of slightly to moderately frail older people. Patient Education and Counseling, 61, 219-227.

Goedendorp, M. M., \& Steverink, N. (2017). Interventions based on self-management of well-being theory: Pooling data to demonstrate mediation and ceiling effects, and to compare formats. Aging \& Mental Health, 21(9), 947-953. https://doi.org/10.1080/13607863.2016.1182967.

Hauser, R. M., Warren, J. R., Huang, M.-H., \& Carter, W. Y. (2000). Occupational status, education, and social mobility in the meritocracy. In K. Arrow, S. Bowles, \& S. Durlauf (Eds.), Meritocracy and economic inequality (pp. 179-229). Princeton: Princeton University Press.

Hawkley, L. C., \& Cacioppo, J. T. (2010). Loneliness matters: a theoretical and empirical review of consequences and mechanisms. Annals of Behavioral Medicine, 40, 218-227. https://doi.org/10.1007/ s12160-010-9210-8.

Hayes, A. F. (2013). Introduction to mediation, moderation, and conditional process analysis: A regression-based approach. New York, NY: The Guilford Press.

Hofmann, W., Finkel, E. J., \& Fitzsimons, G. M. (2015). Close relationships and self-regulation: How relationship satisfaction facilitates momentary goal pursuit. Journal of Personality and Social Psychology, 109, 434-452. https://doi.org/10.1037/pspi0000020.

Hu, L., \& Bentler, P. M. (1999). Cutoff criteria for fit indexes in covariance structure analysis: Conventional criteria versus new alternatives. Structural Equation Modeling, 6, 1-55.

Jöreskog, K. G. (1971). Simultaneous factor analysis in several populations. Psychometrika, 36, 409-426.

Kenny, D. A. (2011). Measuring model fit. Retrieved June 15, 2015 from http://davidakenny.net/cm/fit. htm.

Khan, A. (2013). Predictors of positive psychological strengths and subjective well-being among North Indian adolescents: Role of mentoring and educational encouragement. Social Indicators Research, 114, 1285-1293. https://doi.org/10.1007/s11205-012-0202-x.

Kremers, I. P., Steverink, N., Albersnagel, F. A., \& Slaets, J. P. J. (2006). Improved self-management ability and well-being in older women after a short group intervention. Aging and Mental Health, 10, 476-484.

Leary, M. R., \& Baumeister, R. F. (2000). The nature and function of self-esteem: Sociometer theory. In M. Zanna (Ed.), Advances in experimental social psychology (Vol. 32, pp. 1-62). San Diego: Academic Press.

Leary, M. R., Kelly, K. M., Cottrell, C. A., \& Schreindorfer, L. S. (2013). Construct validity of the Need to Belong Scale: Mapping the nomological network. Journal of Personality Assessment, 95, 610-624. https://doi.org/10.1080/00223891.2013.819511.

Lindenberg, S. (2013). Social rationality, self-regulation and well-being: The regulatory significance of needs, goals, and the self. In R. Wittek, T. A. B. Snijders, \& V. Nee (Eds.), Handbook of rational choice social research (pp. 72-112). Stanford: Stanford University Press.

Linley, P. A., Nielsen, K. M., Wood, A. M., Gillett, R., \& Biswas-Diener, R. (2010). Using signature strengths in pursuit of goals: Effects on goal progress, need satisfaction, and well-being, and implications for coaching psychologists. International Coaching Psychology Review, 5(1), 6-15. 
Liu, W., Li, Z., Ling, Y., \& Cai, T. (2016). Core self-evaluations and coping styles as mediators between social support and well-being. Personality and Individual Differences, 88, 35-39.

Lucas, R. E., Diener, E., \& Suh, E. (1996). Discriminant validity of well-being measures. Journal of Personality and Social Psychology, 71, 616-628.

Luthans, F., \& Youssef-Morgan, C. M. (2017). Psychological capital: An evidence-based positive approach. Annual Review of Organizational Psychology and Organizational Behavior, 4, 339-366. https://doi.org/10.1146/annurev-orgpsych-032516-113324.

Maccoby, E. E. (1990). Gender and relationships: A developmental account. American Psychologist, 45, 513-520.

Mayr, U., Wozniak, D., Davidson, C., Kuhns, D., \& Harbaugh, W. T. (2012). Competitiveness across the life span: The feisty fifties. Psychology and Aging, 27, 278-285. https://doi.org/10.1037/a0025655.

$\mathrm{Ng}$, W., \& Diener, E. (2014). What matters to the rich and the poor? Subjective well-being, financial satisfaction, and postmaterialist needs across the world. Journal of Personality and Social Psychology, 107, 326-338. https://doi.org/10.1037/a0036856.

Nieboer, A. P., \& Cramm, J. M. (2017). Age-friendly communities matter for older people's well-being. Journal of Happiness Studies. https://doi.org/10.1007/s10902-017-9923-5.

Nieboer, A. P., \& Cramm, J. M. (2018). How do older people achieve well-being? Validation of the Social Production Function Instrument for the level of well-being-short (SPF-ILs). Social Science and Medicine, 211, 304-313.

Nieboer, A., \& Lindenberg, S. (2002). Substitution, buffers and subjective well-being: A hierarchical approach. In E. Gullone \& R. A. Cummins (Eds.), The universality of subjective wellbeing indicators: A multidisciplinary and multi-national perspective (Social Indicators Book Series 16 (pp. 175-189). Dordrecht, NL: Kluwer Academic Publishers.

Nieboer, A., Lindenberg, S., Boomsma, A., \& Van Bruggen, A. C. (2005). Dimensions of well-being and their measurement: The SPF-IL Scale. Social Indicators Research, 73, 313-353.

Peeters, F. P. M. L., Ponds, R. W. H. M., \& Vermeeren, M. T. G. (1996). Affectiviteit en zelfbeoordeling van depressie en angst. Tijdschrift voor Psychiatrie, 38, 240-250.

Scholtens, S., Smidt, N., Swertz, M. A., Bakker, S. J. L., Dotinga, A., Vonk, J. M., et al. (2015). Cohort Profile: LifeLines, a three-generation cohort study and biobank. International Journal of Epidemiology, 44, 1172-1180. https://doi.org/10.1093/ije/dyu229.

Schreiber, J. B., Nora, A., Stage, F. K., Barlow, E. A., \& King, J. (2006). Reporting structural equation modeling and confirmatory factor analysis results: A review. The Journal of Educational Research, 99(6), 323-338.

Schuurmans, H., Steverink, N., Frieswijk, N., Buunk, B. P., Slaets, J. P. J., \& Lindenberg, S. (2005). How to measure self-management abilities in older people by self-report. The development of the SMAS-30. Quality of Life Research, 14, 2215-2228.

Sheldon, K. M., \& Lyubomirksy, S. (2006). How to increase and sustain positive emotion: The effects of expressing gratitude and visualizing best possible selves. Journal of Positive Psychology, 1, 73-82.

Snyder, C. R., Harris, C., Anderson, J. R., Holleran, S. A., Irving, L. M., Sigmon, S. T., et al. (1991). The will and the ways: Development and validation of an individual-differences measure of hope. Journal of Personality and Social Psychology, 60, 570-585.

Snyder, C. R., Rand, K. L., \& Sigmon, D. R. (2002). Hope theory: A member of the positive psychology family. In C. R. Snyder \& S. J. Lopez (Eds.), Handbook of positive psychology (pp. 257-276). New York, NY: Oxford University Press.

Snyder, M., \& Swann, W. B. (1978). Behavioral confirmation in social interaction: From social perception to social reality. Journal of Experimental Social Psychology, 14, 148-162.

Steiger, J. H. (1980). Tests for comparing elements of a correlation matrix. Psychological Bulletin, 87, $245-251$.

Steinmetz, H., Schmidt, P., Tina-Booh, A., Wieczorek, S., \& Schwartz, S. H. (2009). Testing measurement invariance using multigroup CFA: Differences between educational groups in human values measurement. Quality and Quantity: International Journal of Methodology, 43, 599-616. https:// doi.org/10.1007/s11135-007-9143-x.

Steverink, N. (2014). Successful development and aging: Theory and intervention. In N. A. Pachana \& K. Laidlaw (Eds.), The Oxford handbook of clinical geropsychology (pp. 84-103). Oxford: Oxford University Press.

Steverink, N., \& Lindenberg, S. (2006). Which social needs are important for subjective wellbeing? What happens to them with aging? Psychology and Aging, 21, 281-290.

Steverink, N., \& Lindenberg, S. (2008). Do good self-managers have less physical and social resource deficits and more well-being in later life? European Journal of Ageing, 5, 181-190. https://doi. org/10.1007/s10433-008-0089-1. 
Steverink, N., Veenstra, R., Oldehinkel, A. J., Gans, R. O. B., \& Rosmalen, J. G. M. (2011). Is social stress in the first half of life detrimental to later physical and mental health in both men and women? European Journal of Ageing, 8, 21-30.

Stillman, T. F., Baumeister, R. F., Lambert, N. M., Crescioni, A. W., DeWall, C. N., \& Fincham, F. D. (2009). Alone and without meaning: Life loses meaning following social exclusion. Journal of Experimental and Social Psychology, 45, 686-694.

Tay, L., \& Diener, E. (2011). Needs and subjective well-being around the world. Journal of Personality and Social Psychology, 101, 354-365. https://doi.org/10.1037/a0023779.

Taylor, S. E., Dickerson, S. S., \& Cousino Klein, L. (2002). Toward a biology of social support. In C. R. Snyder \& S. J. Lopez (Eds.), Handbook of positive psychology (pp. 556-569). Oxford: Oxford University Press.

Tiernan, C., Lysack, C., Neufeld, S., Goldberg, A., \& Lichtenberg, P. A. (2014). Falls efficacy and self-rated health in older African American adults. Archives of Gerontology and Geriatrics, 58, 88-94.

Valle, M. F., Huebner, E. S., \& Suldo, S. M. (2006). An analysis of hope as a psychological strength. Journal of School Psychology, 44, 393-406. https://doi.org/10.1016/j.jsp.2006.03.005.

Van Baarsen, B., Snijders, T. A. B., Smit, J. H., \& Van Duijn, M. A. J. (2001). Lonely but not alone: Emotional isolation and social isolation as two distinct dimensions of loneliness in older people. Educational and Psychological Measurement, 61, 119-135. https://doi.org/10.1177/00131640121971103.

Van Bruggen, A. (2001). Individual production of social well-being: An exploratory study. Doctoral dissertation, University of Groningen, The Netherlands. Retrieved from http://dissertations.ub.rug.nl/facul ties/gmw/2001/a.c.van.bruggen/.

Watson, D., Clark, L. A., \& Tellegen, A. (1988). Development and validation of brief measures of positive and negative affect: The PANAS Scales. Journal of Personality and Social Psychology, 54, 1063-1070.

Weiss, R. S. (1973). Loneliness: The experience of emotional and social isolation. Cambridge, MA: MIT Press.

Wood, A. M., Linley, P. A., Maltby, J., Kashdan, T. B., \& Hurling, R. (2011). Using personal and psychological strengths leads to increases in well-being over time: A longitudinal study and the development of the strengths use questionnaire. Personality and Individual Differences, 50, 15-19. https://doi. org/10.1016/j.paid.2010.08.004.

Zhou, X., Wu, X., \& Zhen, R. (2018). Self-esteem and hope mediate the relations between social support and post-traumatic stress disorder and growth in adolescents following the Ya' an earthquake. Anxiety Stress and Coping, 31, 32-45. https://doi.org/10.1080/10615806.2017.1374376.

Publisher's Note Springer Nature remains neutral with regard to jurisdictional claims in published maps and institutional affiliations.

\section{Affiliations}

\section{Nardi Steverink ${ }^{1,2} \mathbb{D} \cdot$ Siegwart Lindenberg ${ }^{1,3} \cdot$ Tali Spiegel $^{4} \cdot$ Anna P. Nieboer $^{5}$}

1 Department of Sociology/ICS, University of Groningen, Groningen, The Netherlands

2 Department of Health Psychology, University Medical Center Groningen, University of Groningen, Groningen, The Netherlands

3 Department of Social Psychology, Tilburg University, Tilburg, The Netherlands

4 Department of Sociology, Utrecht University, Utrecht, The Netherlands

5 School of Health Policy and Management, Erasmus University Rotterdam, Rotterdam, The Netherlands 